\title{
On the Evolution of Strain and Electrical Properties in As-Grown and Annealed Si:P Epitaxial Films for Source-Drain Stressor Applications
}

\author{
Sathish kumar Dhayalan, (1),2,a,z Jiri Kujala, ${ }^{3}$ Jonatan Slotte, ${ }^{3}$ Geoffrey Pourtois, ${ }^{2,4, *}$ \\ Eddy Simoen, ${ }^{2,5, * *}$ Erik Rosseel, ${ }^{2}$ Andriy Hikavyy, ${ }^{2}$ Yosuke Shimura, ${ }^{1,2, a}$ Roger Loo, ${ }^{2, *}$ \\ and Wilfried Vandervorst ${ }^{1,2}$
}

\author{
${ }^{I}$ Department of Physics, Celestijnenlaan 200D, 3001 Heverlee, Belgium \\ ${ }^{2}$ imec vzw, 3001 Heverlee, Belgium \\ ${ }^{3}$ Department of Applied Physics, Aalto University, FI-00076 AALTO, Finland \\ ${ }^{4}$ PLASMANT, Department of Chemistry, University of Antwerp, 2610 Antwerp, Belgium \\ ${ }^{5}$ Department of Solid State Sciences, Ghent University, 9000 Belgium
}

\begin{abstract}
Heavily P doped Si:P epitaxial layers have gained interest in recent times as a promising source-drain stressor material for $\mathrm{n}$ type FinFETs (Fin Field Effect Transistors). They are touted to provide excellent conductivity as well as tensile strain. Although the as-grown layers do provide tensile strain, their conductivity exhibits an unfavorable behavior. It reduces with increasing $\mathrm{P}$ concentration $\left(\mathrm{P}>1 \mathrm{E} 21 \mathrm{at} / \mathrm{cm}^{3}\right)$, accompanied by a saturation in the active carrier concentration. Subjecting the layers to laser annealing increases the conductivity and activates a fraction of $\mathrm{P}$ atoms. However, there is also a concurrent reduction in tensile strain $(<1 \%)$. Literature proposes the formation of local semiconducting $\mathrm{Si}_{3} \mathrm{P}_{4}$ complexes to explain the observed behaviors in Si:P $[\mathrm{Z}$. Ye et al., ECS Trans., 50(9) 2013, p. 1007-1011]. The development of tensile strain and the saturation in active carrier is attributed to the presence of local complexes while their dispersal on annealing is attributed to strain reduction and increase in active carrier density. However, the existence of such local complexes is not proven and a fundamental void exists in understanding the structure-property correlation in Si:P films. In this respect, our work investigates the reason behind the evolution of strain and electrical properties in the as-grown and annealed Si:P epitaxial layers using ab-initio techniques and corroborate the results with physical characterization techniques. It will be shown that the strain developed in Si:P films is not due to any specific complexes while the formation of Phosphorus-vacancy complexes will be shown responsible for the carrier saturation and the increase in resistivity in the as-grown films. Interstitial/precipitate formation is suggested to be a reason for the strain loss in the annealed films.

(C) The Author(s) 2018. Published by ECS. This is an open access article distributed under the terms of the Creative Commons Attribution Non-Commercial No Derivatives 4.0 License (CC BY-NC-ND, http://creativecommons.org/licenses/by-nc-nd/4.0/), which permits non-commercial reuse, distribution, and reproduction in any medium, provided the original work is not changed in any way and is properly cited. For permission for commercial reuse, please email: oa@electrochem.org. [DOI: 10.1149/2.0071805jss]
\end{abstract}

(cc) BY-NC-ND

Manuscript submitted January 15, 2018; revised manuscript received April 19, 2018. Published May 1, 2018.

The microelectronics industry is currently in the 14 nm node where 3 dimensional(3D) Si FinFET devices are already in production. Although new technologies and materials (e.g. Tunnel FETs, III-V channels, Ge channels etc.) have been proposed for the future transistor nodes, several technological and reliability challenges need to be overcome before those devices can be realized. ${ }^{1,2}$ Hence, the next couple of nodes (possibly up to $5 \mathrm{~nm}$ ) may continue to be dominated by the Si FinFET technology. The performance of the Si FinFETs can be further scaled by the re-introduction of the source-drain S/D stressors that were first introduced in the $65 \mathrm{~nm}$ node for planar transistors. Typically, $\mathrm{SiGe}(\mathrm{B}) \mathrm{S} / \mathrm{D}$ stressors that provide compressive stress are used for $\mathrm{p}$ type FinFETs ${ }^{3}$ while $\mathrm{Si}: \mathrm{C}(\mathrm{P})$ ones that provide tensile stress are for n-FinFETs. ${ }^{4}$ Out of the two, the Si:C(P) stressors suffer from the problem of increasing resistivity with increasing $\mathrm{C}$ contents. ${ }^{5,6}$ Subjecting the as-grown $\mathrm{Si}: \mathrm{C}(\mathrm{P})$ layers to laser or spike annealing does not result in any significant improvement in the conductivity or carrier concentration. ${ }^{5,6}$ Hence, instead of $\mathrm{Si}: \mathrm{C}(\mathrm{P})$, heavily $\mathrm{P}$ doped $\mathrm{Si}: \mathrm{P}$ films have gained prominent interest in recent times. As $\mathrm{P}$ is an n-type dopant with a reduced covalent radius, $\mathrm{Si}: \mathrm{P}$ films are expected to offer the combined advantages of better conductivity as well as tensile strain. ${ }^{6-9}$ This motivation has led to a surge in the publications pertaining to the processing aspects of $\mathrm{Si}: \mathrm{P}$ films $\mathrm{s}^{6,8-11}$ and publications discussing the evolution of resistivities in the as grown and annealed Si:P films. ${ }^{6,9,12}$ While the strain developed in the as-grown Si:P films increases with the total $\mathrm{P}$ concentration, the values of resistivity corresponding to those $\mathrm{P}$ concentrations were higher than the desired values for S/D applications i.e., higher than 0.3 mohm.cm. ${ }^{9}$ A commonly used laser annealing process leads to reduction in resistivity

\footnotetext{
*Electrochemical Society Member.

**Electrochemical Society Fellow.

${ }^{\text {aPresent }}$ address: Shizuoka University, Japan.

${ }^{\mathrm{z}}$ E-mail: sathish.nano.epi@gmail.com
}

concurrent with an undesirable reduction in tensile strain. ${ }^{9}$ To explain the observed behaviors from a microstructural perspective, Ye et al., hypothesized that the strain developed in the films was due to the formation of local $\mathrm{Si}_{3} \mathrm{P}_{4}$ complexes which were of semiconducting nature. ${ }^{9}$ Increasing resistivity with $\mathrm{P}$ concentration was also attributed to the semiconducting nature of these complexes. On annealing, the complexes dissolved thereby reducing the resistivity, while promoting strain loss at the same time. Although this hypothesis explains the observed behaviors in Si:P films, it is not substantiated by any theoretical or experimental proof. Hence, a fundamental gap exists in understanding the microstructure of $\mathrm{Si}: \mathrm{P}$ films in relation to strain and electrical properties. It is also technologically important to address this gap, because if the local complexes are indeed responsible for strain, it defies the main advantage of using Si:P films i.e., the requirement of low resistivity for $\mathrm{S} / \mathrm{D}$ applications might necessitate the dispersal of all the local complexes whereby the benefit of strain would be lost. In this case, the industry might need to look for alternative S/D stressor materials for n-FinFET applications. On the other hand, if the developed strain is not specifically due to these local complexes, there is a room to use Si:P films to scale up the performance of $n$ FinFETs. Therefore, a concrete microstructural reasoning behind the evolution of strain and conductivity in $\mathrm{Si}: \mathrm{P}$ films is relevant to decide their applicability as a scaling vehicle for n-FinFETs. Providing this fundamental understanding is the prime focus of this work.

This paper is organized as follows: First, we will briefly review our results on the impact of $\mathrm{P}$ incorporation on the structural and the electrical properties of Si:P films, which we reported earlier. ${ }^{6}$ After this, the local phase formation hypothesis is investigated using Density Functional Theory (DFT). DFT results are used to provide microstructural reasoning behind the evolution of strain and electrical properties and these results will also be corroborated using physical characterization techniques such as Positron Annihilation Spectroscopy (PAS) and Rutherford Backscattering Ion channeling measurements (RBS). 
(a)

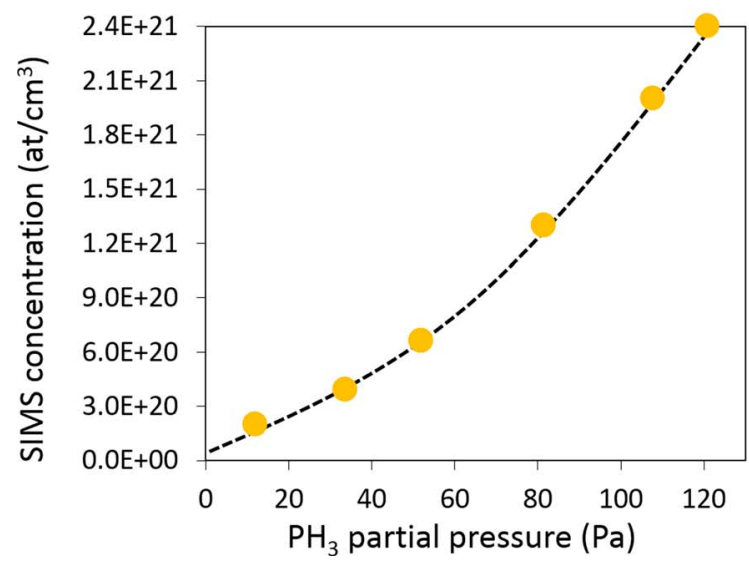

(b)

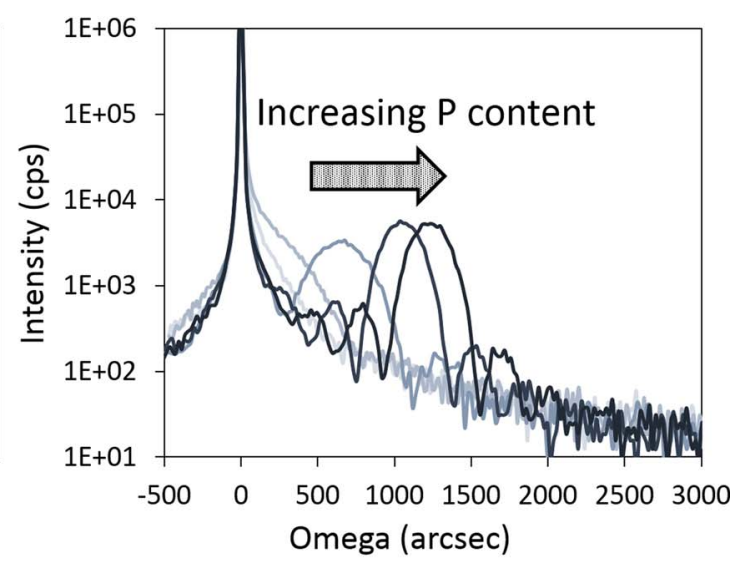

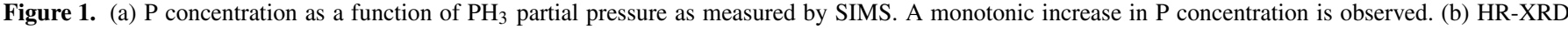

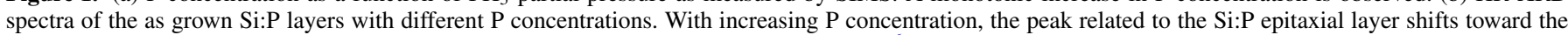
right, reflecting the development of tensile strain (Figures are taken from our previous work ${ }^{6}$ ).

\section{Experimental and Simulation Details}

Growth and characterization details.-Si:P layers were deposited on Si (001) substrates using ASM Intrepid XP- a reduced pressure chemical vapor deposition tool. The layers were grown at $675^{\circ} \mathrm{C}$ using dicholorosilane (DCS), a Si precursor and $\mathrm{PH}_{3}$, a P precursor. The total deposition pressure was maintained at $26665 \mathrm{~Pa}$. For all the as-grown layers, the epi layer thickness was targeted to be close to $60 \mathrm{~nm}$. High Resolution XRD (HR-XRD) was used to examine the strain developed in Si:P layers. Fitting of HR-XRD spectra was carried out using RADS software from Bruker. ${ }^{13}$ Secondary Ion Mass Spectrometry (SIMS) was used to assess the total $\mathrm{P}$ concentration. The resistivity, carrier concentration and hall mobilities were measured using a 4 probe micro hall measurement set up.

Simulation details. - The ab-initio simulations were carried out on a 216 atoms unit cell using the quantum espresso ${ }^{14}$ package combined with Vanderbilt pseudopotentials. A $340 \mathrm{eV}$ kinetic energy cut off and gamma $\mathrm{k}$ point mesh sampling were used, combined with the Perdew-Burke-Ernzerhof (PBE) exchange correlational function. ${ }^{15}$ The atomic positions of the 216 atoms unit cell were then relaxed until the forces acting on the entire unit became less than $1 \mathrm{E}-3 \mathrm{kbar}$. The bader population analysis ${ }^{16,17}$ was discretized with a grid size of $250 \times 250 \times 250$ points.

PAS characterization details.-Doppler Broadening Spectroscopy (DOBS) measurements have been performed in this work using a slow positron beam with a monoenergetic variable energy $(0.5-25 \mathrm{keV})$. The variable energy beam also enables depth profiling. The Doppler broadening of the $511 \mathrm{keV}$ annihilation line is measured with a high purity Ge detector with an energy resolution of $1.15 \mathrm{keV}$ at $511 \mathrm{keV}$. The integration window for the $\mathrm{S}$ and the $\mathrm{W}$ parameters are chosen in the energy range of $|\mathrm{p}|<0.4$ a.u. (atomic unit) and 1.2 a.u. $<|\mathrm{p}|<4.0$ a.u., respectively ( $|\mathrm{p}|$ represents momentum).

The surface oxide was removed by etching the samples in HF acid prior to the measurements. Otherwise, the positrons may interact with the traps/core electrons within the native oxide and may mask the $S$ and $\mathrm{W}$ parameters of the Si:P layer. ${ }^{18}$ Removing the surface oxide is indeed shown to improve the sensitivity of PAS close to the surface. ${ }^{19,20}$ To probe the epi layer, a narrow positron implantation profile is desired (corresponding to energies $<2 \mathrm{keV}$ ). After implantation, the positron starts to diffuse. The positron diffusion length is of the order of $100 \mathrm{~nm}$ in a positron trap free semiconductor. On the other hand, the presence of vacancy (V) defects in the order of $10^{17}-10^{18} \mathrm{~cm}^{-3}$ reduces the positron diffusion length by approximately an order of magnitude. Consequently, the positron is trapped in the major portion of the epi layer and is sensitive to the defects present in it. ${ }^{21}$ For the Si:P layers, the width of the $\mathrm{e}^{+}$-implanted profile is approximately the same size as the average implantation depth and possess a narrow implantation profile that primarily covers the epi layer.

\section{Review on the Impact of P Incorporation on Structural and Electrical Properties of Si:P Films}

In view of the crystalline quality being primarily dependent on the concentration and the type of the added impurities, $\mathrm{P}$ incorporation has been studied as a function of $\mathrm{PH}_{3}$ partial pressure, while maintaining fixed partial pressures of DCS and the carrier gas $\left(\mathrm{H}_{2}\right)$. The incorporated atomic $P$ concentration as measured by SIMS is shown in Fig. 1a. A monotonic increase in $\mathrm{P}$ concentration is observed similar to the reports from other groups. ${ }^{8,10,11}$ An effect stemming from $\mathrm{P}$ incorporation is the development of lattice strain in $\mathrm{Si}: \mathrm{P}$ films as shown in the (004) HR-XRD scans (Fig. 1b). The epi layer peak positions clearly shift toward higher angles with increasing total $\mathrm{P}$ concentrations, confirming the increase in tensile strain with total $\mathrm{P}$ concentration. For the process conditions used in this work, the $\mathrm{Si}: \mathrm{P}$ epi layers underwent epitaxial breakdown beyond a maximum of $4.6 \%\left(\sim 2.3 \mathrm{E} 21 \mathrm{at} / \mathrm{cm}^{3}\right)$ total $\mathrm{P}$ concentration. Due to this problem, the layers discussed in the present work are limited to a maximum $P$ concentration of $4.6 \%$ and the electrical properties of the layers up to this concentration range are presented next.

The value of resistivities, the corresponding Hall mobilities and the active carrier concentrations of the as grown films with different $\mathrm{P}$ concentrations are shown in Figs. $2 \mathrm{a}, 2 \mathrm{~b}$ and $2 \mathrm{c}$ respectively. The resistivity first reduces with increasing $\mathrm{P}$ doping and reaches a minimum for the total $\mathrm{P}$ concentration of about $2.3 \%$ after which it increases again. Typically, the values of resistivities reported in the decreasing trend are much higher than the case when all the incorporated $\mathrm{P}$ concentration would be active. Indeed, the active carrier concentration starts to saturate with increasing $\mathrm{P}$ concentration and at a maximum total $\mathrm{P}$ concentration of $4.6 \%$, only $10 \%$ are active (Fig. 2d). Whereas, the mobility continues to decrease due to existing active ionic scattering centers. The net result of carrier saturation and decreasing hall mobility is the increase in resistivity beyond a total $\mathrm{P}$ concentration of $\sim 2.3 \%$. Nevertheless, the resistivities reported in the present work are similar to the ones previously reported by Ye et al., ${ }^{9}$ and Li et al. ${ }^{12}$ Sub-melt millisecond laser annealing (LA) is one of the proven techniques to optimize the resistivity, ${ }^{9}$ which has been used in the current work as well. The resistivities, the Hall mobilities and the active carrier concentrations of the laser annealed layers are shown in Figs. 2a-2c using open symbols. It can be seen that after annealing, the resistivity evidently reduces to a minimum value and saturates. 
(a)
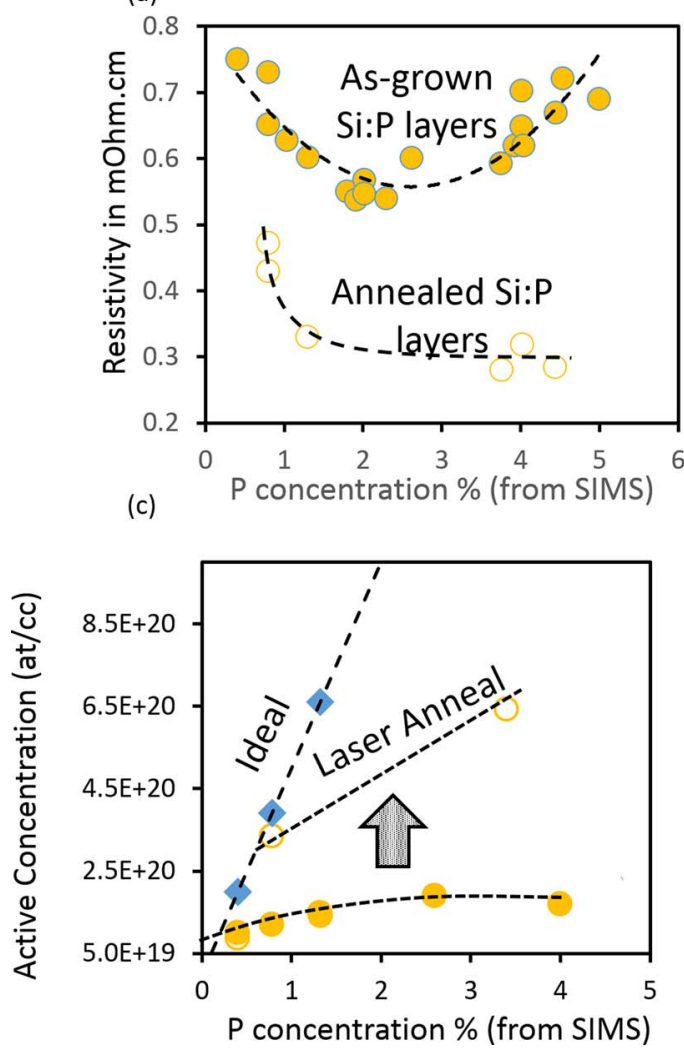

(b)

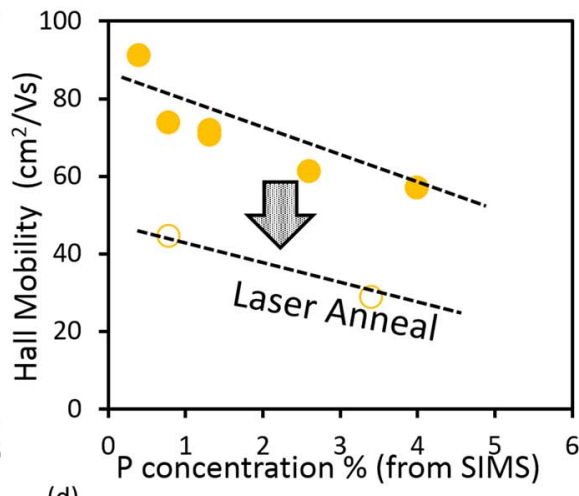

(d)

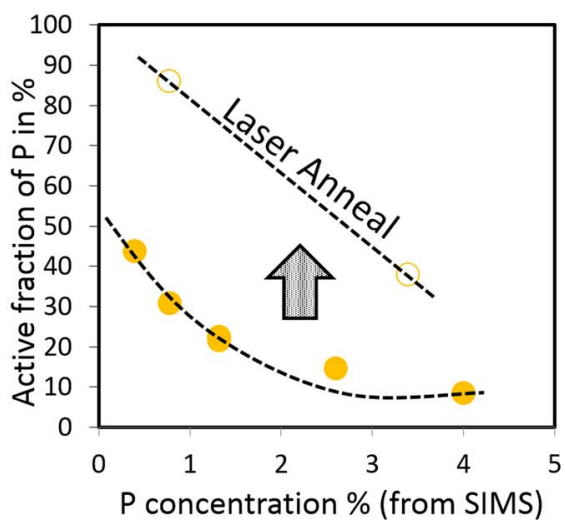

Figure 2. Electrical characteristics of the as grown (closed symbols) and annealed Si:P films (open symbols). (a) Resistivity as function of P concentration. (b) Hall mobility of selected as grown and annealed Si:P layers. (c) Active carrier concentration as function of P concentration Filled diamonds represent 100\% active concentration at different total concentrations. The experimentally measured active P fraction is shown in (d) (Figures are adapted from Ref. 6).

The hall mobility of the annealed layers is lower than the values of the as-grown layers. Thanks to the increased dopant activation $(\sim 50 \%)$ and the consequential increase in ionized impurity scattering, which is much higher than the one in the as-grown films. Additionally, at these active concentrations, plasmon scattering also contributes to mobility losses. ${ }^{22}$ Although annealing leads to an activation of about $50 \%$ of the total $\mathrm{P}$ concentration compared to the as-grown layers, this improvement comes at a cost of slight reduction in the tensile strain $(<1 \%)$ (Fig. 3). Literatures indicate that increasing the annealing temperature or the pulse time can further increase the carrier activation,

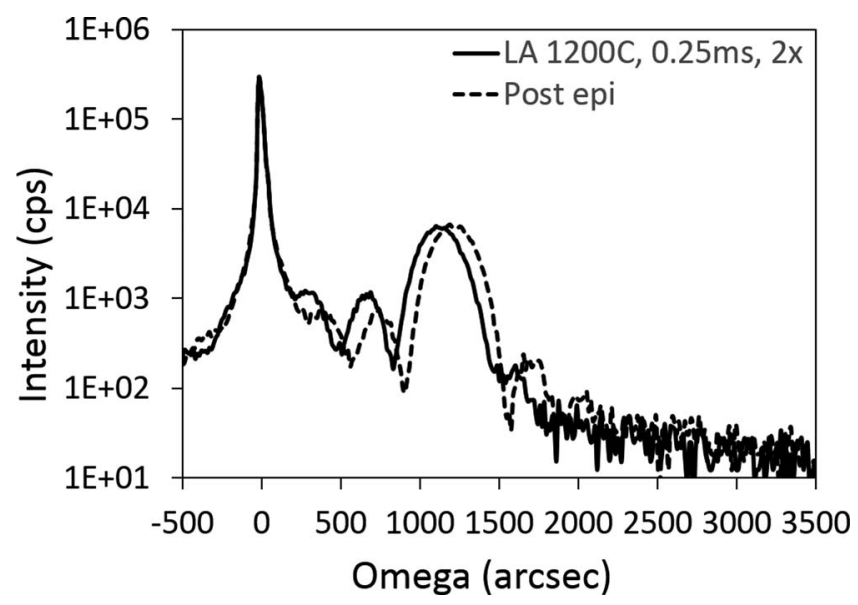

Figure 3. XRD spectra of the Si:P layer with a total P concentration of $4.6 \%$, before and after LA. Annealing leads to a peak shift toward the left indicating strain loss (Figure taken from Ref. 6). but with a significant reduction in tensile strain (close to $\sim 30 \%$ strain loss). ${ }^{9}$ Layers for S/D applications require an optimal balance between tensile strain as well as dopant activation. Hence, to limit the strain reduction, we have not used high temperature or increased pulse time in our anneals, limiting the strain loss to less than $1 \%$.

Thus, the as-grown Si:P films exhibit high resistivities and a saturation in the active carrier concentration. Laser annealing increases the active carrier concentration leading to a reduction in the resistivity concurrent with a small reduction in tensile strain. To explain this intriguing evolution of strain and electrical properties, one needs to understand the structure property correlation in Si:P films. Particularly, the validity of local $\mathrm{Si}_{3} \mathrm{P}_{4}$ complex formation hypothesis needs to be addressed. In this context, we will use DFT to systematically investigate,

a) The thermodynamic favorability for the formation of local $\mathrm{Si}_{3} \mathrm{P}_{4}$ complexes,

b) If favorable, are the complexes responsible for the observed evolution in tensile strain and electrical properties in the as-grown and laser annealed Si:P layers?

It will be shown that vacancy centered $\mathrm{Si}_{3} \mathrm{P}_{4}$ complexes (also referred to as $\mathrm{P}_{4} \mathrm{~V}$ ) are indeed thermodynamically spontaneous in the Si:P layers. Atomistically, their favorability is proposed to be a result from bond relaxations provided to $\mathrm{P}$ atoms by the vacancies. Whereas, the development of tensile strain in the as-grown films is not owing to these complexes but is purely due to the differences in the covalent radii between $\mathrm{P}$ and $\mathrm{Si}$. Formation of $\mathrm{P}$ interstitials or precipitates will be shown to be responsible for strain loss after annealing. Further, the formation of $\mathrm{P}_{4} \mathrm{~V}$ complexes at high $\mathrm{P}$ concentration is shown to be responsible for carrier saturation in the as-grown films. The existence of these complexes will also be confirmed using PAS. 


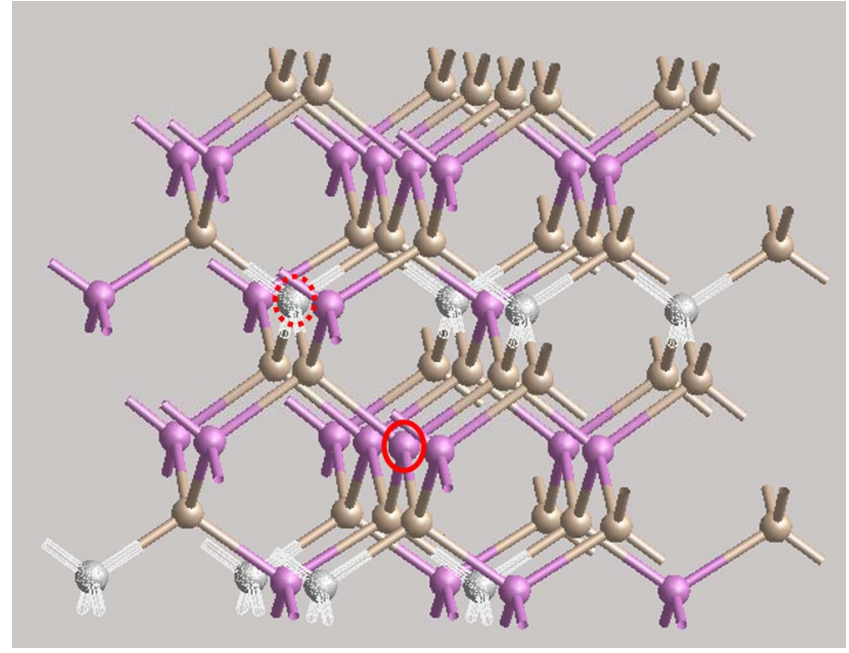

Figure 4. Illustration of the pseudocubic $\mathrm{Si}_{3} \mathrm{P}_{4}$ phase. For clarity, the vacancies are shown using gray ball with white wireframe bonds. The pseudocubic structure has two equivalent structures depending on whether vacancy centered (dotted circle) or Si centered configurations (solid circle) are considered. In the vacancy centered configuration, $4 \mathrm{P}$ atoms cluster around a single vacancy while in a $\mathrm{Si}$ centered one, $4 \mathrm{P}$ atoms cluster around a single $\mathrm{Si}$ atom.

\section{Understanding the Structure of Si:P Films}

Thermodynamic favorability of $\mathrm{Si}_{3} \boldsymbol{P}_{4}$ complex. $-\mathrm{Si}_{3} \mathrm{P}_{4}$ is a pseudocubic phase whose repetitive 3D structure is shown in Fig. 4. The $\mathrm{Si}_{3} \mathrm{P}_{4}$ phase was first proposed by Huang et al., based on their first principles simulation results for semiconducting compounds composed of group IV and group III elements. ${ }^{23}$ The structure appears as a defective zinc blende with two equivalent configurations. From a vacancy centered perspective, four $\mathrm{P}$ atoms are seen bonded to the vacancy (shown as gray ball with white wireframe bonds) while from a Si centered perspective, it has an equivalent structure where four $\mathrm{P}$ atoms (shown as brownish yellow sphere) are bonded to a single $\mathrm{Si}$ atom (shown as pink sphere). In both equivalent structures, it is seen that $\mathrm{P}$ atoms are present as second nearest neighbors ( $2 \mathrm{nn})$ and in the former case, $P$ and vacancy are present as first nearest neighbors $(1 \mathrm{nn})$. The natural first step to study about the formation of these structures involves a systematic investigation of the interaction between P-P and $\mathrm{P}-\mathrm{V}$ to assess if such nearest neighbor interactions are possible.

Interaction between $P$-P. - In a silicon unit cell containing 216 atoms, two $\mathrm{P}$ atoms (labelled as $\mathrm{P} 1$ and $\mathrm{P} 2$ ), were randomly placed at different radial distances from each other. The unit cell was relaxed and the resulting total energy difference with respect to the reference energy, which will be defined shortly, is shown in Fig. 5.

As the considered system is confined to 216 atoms, the maximum distance to which the second $\mathrm{P}$ atom $(\mathrm{P} 2)$ can be positioned from the first one (P1) without interfering with the imposed periodic boundary conditions, is $12 \AA$, and the total energy of the system at $12 \AA$ is defined as the reference minimum energy for this calculation. Referencing to this energy, it is seen that the presence of two $\mathrm{P}$ atoms in their immediate vicinity leads to an increase in the total energy and the energy difference decreases as the $\mathrm{P}$ atoms occupy positions farther and farther apart. The positive kink computed for a radial distance at $5.9 \AA$ is attributed to a specific configuration where two P atoms occupy positions along a linear chain leading to a maximum stress transfer. ${ }^{24}$ Whenever the difference in total energy between the considered configurations and the reference case (P2 located at $12 \AA$ from $\mathrm{P} 1$ ), is lower or equal to the thermal energy at $300 \mathrm{~K}$, i.e. $26 \mathrm{meV}$, the configuration is considered to be stable. Such a stable configuration manifests when $\mathrm{P}$ atoms are located at least $6.6 \AA$ from each other. Therefore, from an energetic perspective, a $\mathrm{P}$ atom likes to stay at least 4 atomic sites away from another $\mathrm{P}$ atom. Similar behaviors have

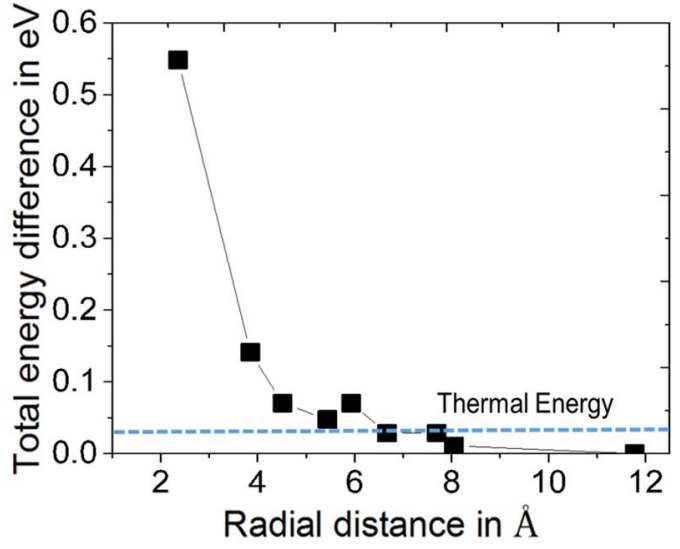

Figure 5. Evolution of the total energy difference as calculated for two substitutional $\mathrm{P}$ atoms in the Si lattice as function of their radial separation distances. From a minimum separation distance of $6.6 \mathrm{~A}$, all the values are below the thermal energy (26 meV).

been found for simulations with higher $\mathrm{P}$ doping concentrations (up to $4.6 \%$ ). However, with increasing $\mathrm{P}$ concentration, the maximum distance to which the $\mathrm{P}_{\mathrm{n}}$ atom can be positioned without interacting with the existing $\mathrm{P}$ atoms, becomes reduced owing to the limitation in the geometrical size of the unit cell. Nevertheless, in all cases the substitutional $\mathrm{P}$ atoms always favor to stay as far away as possible from each other. This is due to the fact that a pure substitutional $\mathrm{P}$ atom in the $\mathrm{Si}$ lattice is ionized and hence possess a positive core charge. As a result, the coulombic repulsion between the ionized $\mathrm{P}$ atoms prevents the formation of any nearest neighbor configuration in $\mathrm{Si}: \mathrm{P}$ at all concentrations. Hence, in view of similarity we restrict the forthcoming discussions to Si:P layers with $4.6 \% \mathrm{P}$ doping

Similar to $\mathrm{P}$ in $\mathrm{Si}$, a system where the added solute atom gives rise to tensile strain is $\mathrm{Si}: \mathrm{C}$. In $\mathrm{Si}: \mathrm{C}, \mathrm{C}$ atoms tend to arrange themselves as $3 \mathrm{nn}$ to locally relax the bonds, minimizing the strain energy. Hence, the $\mathrm{Si}$ :C system has a distinct energy minimum for $3 \mathrm{nn}$ distribution of $\mathrm{C}$ atoms. ${ }^{24}$ Although $\mathrm{P}$ also gives rise to tensile strain at the macroscopic level, no such minimum energy position appears for the distribution of $\mathrm{P}$ atoms. It appears that the tensile strain alone is not sufficient to overcome the coulombic repulsion between $\mathrm{P}$ atoms and to provide a local strain relieving arrangement. Therefore, if the lattice structure is 'free of defects', this coulombic repulsion is expected to persist for all $\mathrm{P}$ concentration thereby preventing the local clustering of $\mathrm{P}$ atoms. However, the as grown $\mathrm{Si}: \mathrm{P}$ films are not grown under equilibrium conditions and hence under non equilibrium growth, defects such as vacancies can get introduced which can eventually influence the arrangement of $\mathrm{P}$ atoms. Let us now understand how the presence of a vacancy changes the interaction picture.

Influence of vacancy on $P$ arrangement.-We have studied the interaction between P and V in a similar way as that of the P-P interaction. The energy of $\mathrm{P}$ and $\mathrm{V}$ as first nearest neighbor $(1 \mathrm{nn})$ is taken as a reference. For the combination of a single $\mathrm{P}$ atom with a vacancy, the total energy of the system decreases with reduction in the radial distance between the P atom and the vacancy (Fig. 6). This indicates an affinity of $\mathrm{P}$ toward vacancies, which has already been reported by different authors. ${ }^{25}$ As $\mathrm{P}$ atoms and vacancies appear to have an attractive interaction, the spontaneity of $\mathrm{P}-\mathrm{V}$ complex formation at a given growth temperature can be obtained by computing the formation enthalpies. For these calculations, the reference system is a $\mathrm{Si}$ lattice in which pure substitutional $\mathrm{P}$ atoms are separated at least $6 \AA$ away from each other. The calculated formation enthalpy of a $P_{n} V$ complex with $n=1$, is positive and equals to $3.4 \mathrm{eV}$. Surprisingly, the formation enthalpy decreases with increasing number of $P$ atoms (n) and eventually becomes negative $(-0.31 \mathrm{eV})$ for the $\mathrm{P}_{4} \mathrm{~V}$ complex, where the vacancy is surrounded on all sides by $\mathrm{P}$ atoms. This negative 


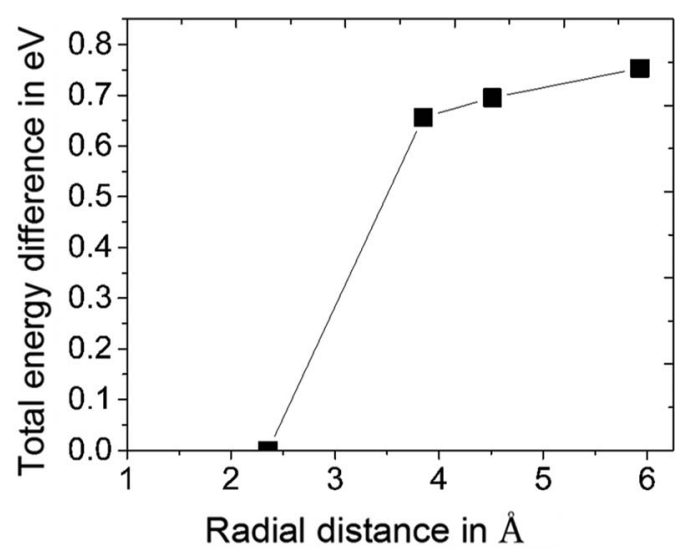

Figure 6. Simulated evolution of the total energy difference between a substitutional $\mathrm{P}$ atom and a vacancy $(\mathrm{V})$ in the $\mathrm{Si}$ lattice with respect to their radial distances of separation.

formation enthalpy indicates that the formation of $\mathrm{P}_{4} \mathrm{~V}$ complexes is thermodynamically spontaneous. This behavior accords well with a similar one reported earlier in the gettering studies of Chen et al. ${ }^{26}$

Thus, $\mathrm{P}_{4} \mathrm{~V}$ clusters are found to be thermodynamically favorable. A question arises whether the formation of any other configurations of $\mathrm{P}_{\mathrm{n}} \mathrm{V}$ clusters is also spontaneous. For e.g., a divacancy configuration formed by the co-existence of two $\mathrm{P}_{3} \mathrm{~V}$ clusters in a linear chain or at the opposite vertices of a six fold hexagon. The formation enthalpies of two such divacancy configurations (Fig. 7) are indeed negative $(-0.16 \mathrm{eV}$ and $-0.6 \mathrm{eV}) .{ }^{27}$ Therefore, our finding suggests that from an energetic perspective, $\mathrm{P}_{\mathrm{n}} \mathrm{V}$ clusters could be present both as monovacancies $\left(\mathrm{P}_{4} \mathrm{~V}\right)$ and divacancies $\left(\mathrm{P}_{6} \mathrm{~V}_{2}\right)$ in the $\mathrm{Si}: \mathrm{P}$ lattice. Hence, $\mathrm{P}$ atoms are expected to form local nearest neighbor arrangements in the presence of vacancies. One may question the reasoning behind the affinity of $\mathrm{P}$ toward vacancies. From an atomistic perspective, this affinity is proposed to result from bond relaxations provided to $\mathrm{P}$ atoms by the vacancies.

To gain insights into the stated effect, we computed the bond lengths (Fig. 8) between pure $\mathrm{Si}$ and $4.6 \% \mathrm{Si}: \mathrm{P}$ with and without $\mathrm{P}-\mathrm{V}$ complexes. The average bond length between pure $\mathrm{Si}$ atoms in a homogeneous $\mathrm{Si}$ system is calculated to be $2.37 \AA$ whereas the experimental one is $2.35 \AA$. The discrepancy between the theory and the measurement is attributed to the nature of the exchange correlation function used in the present work. ${ }^{28}$ On adding a $\mathrm{P}$ atom to the pure $\mathrm{Si}$ system, the $\mathrm{Si}$ atoms (denoted as $\mathrm{Si}_{\mathrm{p}}$ ) in the immediate vicinity of $\mathrm{P}$ are pulled toward the latter. Hence, the $\mathrm{Si}_{\mathrm{p}}-\mathrm{P}$ bond length becomes shorter than the pure $\mathrm{Si}-\mathrm{Si}$ bond length. In a lattice where $\mathrm{P}$ atoms are randomly distributed, the bond distortions introduced by the $\mathrm{P}$ atoms extend up to 2-3 co-ordination spheres. As a result, the strain fields created by different $\mathrm{P}$ atoms overlap each other and act on the $\mathrm{Si}$ neighbors such that the average Si-Si bond length also becomes 2.35 $-2.36 \AA$. Whereas, the P-Si bonds possess an average bond length of $2.34-2.35 \AA$. Although the Si bonds to P atom are shortened, the
$\mathrm{P}$ bonds to $\mathrm{Si}$ are stretched due to the difference in covalent radius between $\mathrm{P}$ and $\mathrm{Si}$.

Let us now look at the role of vacancies in the context of bond relaxations in $\mathrm{Si}: \mathrm{P}$ system. In the presence of vacancies, there is a local relaxation of the bond lengths around $\mathrm{P}$ atoms such that the bond lengths between $\mathrm{P}$ and $\mathrm{Si}_{\mathrm{p}}$ reduce to $2.31 \AA-2.29 \AA$ (Fig. 8d). Although $\mathrm{P}$ bonds relax, the $\mathrm{Si}-\mathrm{Si}$ bond lengths are similar to the vacancy free scenario. Indeed, the bond distortions in the presence of vacancy also extends up to 2- 3 co-ordination spheres where the average $\mathrm{Si}-\mathrm{Si}$ bond length regains its value of $2.36 \AA$. Hence, at high P concentrations, the formation of $\mathrm{P}-\mathrm{V}$ complexes locally relaxes the strained bonds of $\mathrm{P}$ whereas its impact on the Si bonds is nearly unaffected. One can draw parallels between the local strain reduction due to the $\mathrm{P}-\mathrm{V}$ complexes in Si:P films with that of the $3 \mathrm{nn}$ arrangement of $\mathrm{C}$ atoms in the Si:C layers. ${ }^{24}$ In the case of $\mathrm{Si}: \mathrm{C}, \mathrm{C}$ atoms are not charged and hence they occupy a symmetric $3 \mathrm{nn}$ configuration to minimize the local strain. However, in the case of $\mathrm{Si}: \mathrm{P}$, the coulombic repulsion of active $\mathrm{P}$ atoms prevents any form of local neighbor arrangement. Instead, a different way to reduce the local strain is provided by the formation of $\mathrm{P}_{\mathrm{n}} \mathrm{V}$ complexes.

Thus, DFT confirms the spontaneity of $\mathrm{P}_{\mathrm{n}} \mathrm{V}$ complexes and suggests that the affinity of $\mathrm{P}$ and $\mathrm{V}$ results from the local bond relaxations provided by vacancies. Having confirmed the favorability of $\mathrm{P}_{4} \mathrm{~V}$ complexes using DFT, we will now turn to understand if these local complexes describe the evolution of strain and electrical properties in $\mathrm{Si}: \mathrm{P}$ layers.

Microstructural explanation for strain evolution in Si:P films.In this section, we will essentially investigate whether the presence of local complexes gives rise to tensile strain (4.2.1) and the origin of the strain loss upon annealing (4.2.2).

Development of tensile strain in the as-grown films.-An intuitive way to investigate the origin of tensile strain in Si:P films is to extract from the first principles simulations, the lattice constants of $\mathrm{Si}: \mathrm{P}$ layers with and without $\mathrm{P}_{\mathrm{n}} \mathrm{V}$ complexes. Of course, the reference first principle lattice constant of $\mathrm{Si}$ is known prior hand, which facilitates the comparison of the calculated lattice constants with respect to the undoped Si. For simplicity, we will restrict our investigation to Si:P layers with $\mathrm{P}_{4} \mathrm{~V}$ monovacancy complex which is also proposed by $\mathrm{Ye}$ et al. ${ }^{9}$

For the layers without vacancies, active $\mathrm{P}$ atoms were randomly distributed in the Si lattice, and the simulations were carried out for the Si:P layers with $\mathrm{P}$ concentrations ranging from $0.5 \%-4.6 \%$. However, for the layers with $\mathrm{P}_{4} \mathrm{~V}$ complexes, the simulations were performed only for Si:P layers containing $2.7 \%$ and $4.6 \%$ of $\mathrm{P}$ due to the dimension of the unit cell. To form a $\mathrm{P}_{4} \mathrm{~V}$ complex, a minimum of $4 \mathrm{P}$ atoms are required, which corresponds in our model to a $\mathrm{P}$ concentration of $\sim 2 \%$, where all the $\mathrm{P}$ atoms exist as $\mathrm{P}_{4} \mathrm{~V}$ complexes. In reality, a fraction of $\mathrm{P}$ atoms also exists as active dopants and $\mathrm{P}$ concentrations starting from $2.7 \%$ enable us to mimic the reality as much as possible. For $\mathrm{P}$ concentrations below $2.7 \%$, the lattice constants of the layers with $\mathrm{P}_{4} \mathrm{~V}$ complexes were obtained by interpolation. The (i)

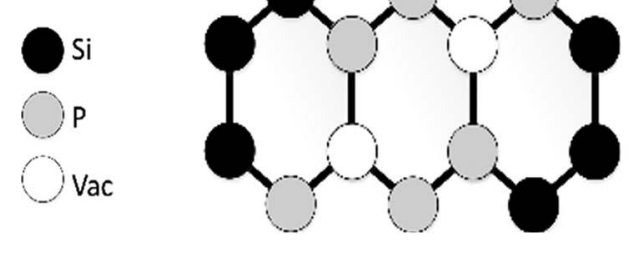

(ii)

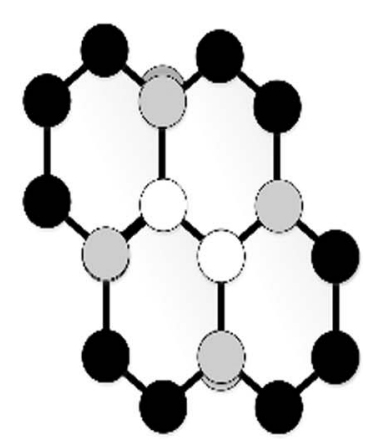

Figure 7. Illustration of two possible configurations of divacancies (for $4.6 \%$ doping) as seen in the (110) direction. The configuration (i) has an enthalpy of formation equal to $-0.16 \mathrm{eV}$, whereas (ii) has an enthalpy of $-0.6 \mathrm{eV}$. (Figure taken from our previous report ${ }^{27}$ ). 
(a)

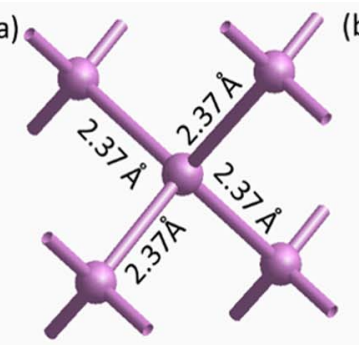

(b)

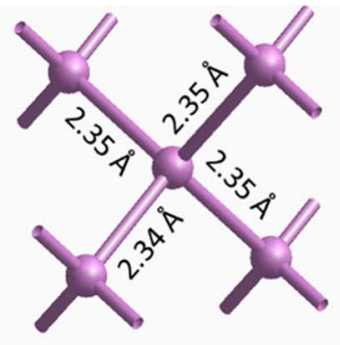

(d)

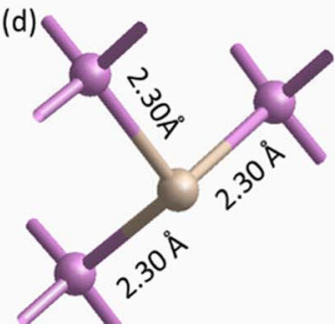

(c)

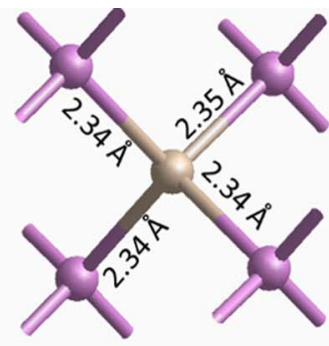

Figure 8. Simulated local bond lengths of $\mathrm{Si}$ and Si:P films. a) Reference $\mathrm{Si}$ (pink) without any $\mathrm{P}$ (golden brown) showing an average bond length of $2.37 \AA$ A. b) In the presence of $\mathrm{P}$, the $\mathrm{Si}$-Si bonds reduce in length within the first 3 co-ordination spheres of $\mathrm{P}$ and (c) P-Si bond lengths are reduced to 2.34-2.35 (d) In the presence of a vacancy, the P-Si bonds are locally relaxed, explaining why $\mathrm{P}$ has an attractive interaction toward the vacancy. relaxed lattice constants with and without $\mathrm{P}_{4} \mathrm{~V}$ complexes, as calculated from the DFT simulations are shown in Fig. 9.

For both films with and without $\mathrm{P}_{4} \mathrm{~V}$ complexes, the relaxed DFT lattice constants reduce with increasing $\mathrm{P}$ concentration. This is a clear indication that with increasing $\mathrm{P}$ concentration, the tensile strain would also increase in Si:P epitaxial layers. However, for a given total $\mathrm{P}$ concentration, one clearly observes that the lattice constants of the films with and without the $\mathrm{P}_{4} \mathrm{~V}$ complexes are quasi identical. This indicates that the strain developed in both films should also be comparable.

This observation provides a counter argument to the hypothesis developed by Ye et al. ${ }^{9}$ Indeed, the assumption that the $\mathrm{P}_{4} \mathrm{~V}$ complexes are responsible for the tensile strain implies that the lattice constants of the films with these complexes should be much lower than the ones without them. However, the existence of comparable lattice constants for both films indicates that $\mathrm{P}_{4} \mathrm{~V}$ complexes do not have any specific role to play in promoting the tensile strain. It develops due to pure differences in the covalent radii between $\mathrm{Si}$ and $\mathrm{P}$.

Thus, it is concluded that the strain developed in Si:P films is not exclusively due to the formation of $\mathrm{P}_{4} \mathrm{~V}$ complexes but purely because of the differences in covalent radii between $\mathrm{P}$ and $\mathrm{Si}$ atoms. As the strain is not exclusively due to $\mathrm{P}_{4} \mathrm{~V}$ complexes, it is not justifiable to ask whether their dissolution leads to the strain loss. Because, their dissolution would essentially result in the activation of more $\mathrm{P}$

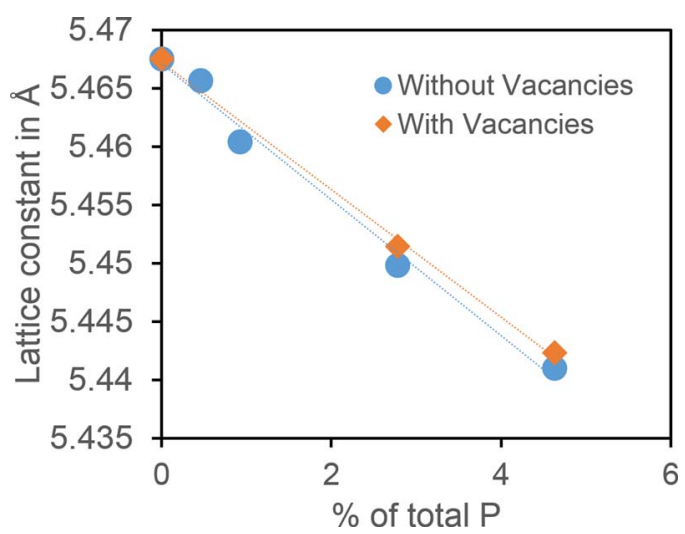

Figure 9. Variation in relaxed lattice constants for the layers with and without vacancy complexes, extracted from DFT simulations. Filled diamonds represent the layers with vacancies and filled circles represent the layers without vacancies. The extracted lattice constants are very similar for both cases. This suggests that the tensile strain is not specifically caused by the said complexes but because of pure differences in covalent radii between $\mathrm{Si}$ and $\mathrm{P}$. atoms, which would have retained the same degree of tensile strain after annealing. However, in reality, there is a strain reduction and the origin of this behavior is addressed next.

Formation of interstitials explaining the strain loss behavior on annealing.-On annealing, the formation of $\mathrm{P}$ interstitials or precipitates is proposed to lead to strain compensation effects in the Si:P layer, thus explaining the strain loss. The $\mathrm{P}$ concentration in the epi layers is much higher than the solid solubility limit. ${ }^{29}$ Hence, annealing provides an external driving force for precipitation. As before, we extracted the lattice constants from DFT simulations to evaluate whether interstitial formation/ precipitation can lead to strain loss. The modeling results are also corroborated with RBS channeling measurements. The simulation details are as follows: For the annealed Si:P layer with $4.6 \%$ total $\mathrm{P}$ concentration, no vacancy complexes are assumed to be present and the total $\mathrm{P}$ concentration is also assumed to be unchanged. In this layer, a certain concentration of $\mathrm{P}$ is assumed to be activated, while the remaining one is assumed to be present as interstitials. Their relaxed lattice constants are extracted from the DFT simulations and are plotted in Fig. 10.

It is seen that with increasing concentration of interstitials, the relaxed lattice constants increase. This reflects a decrease in tensile

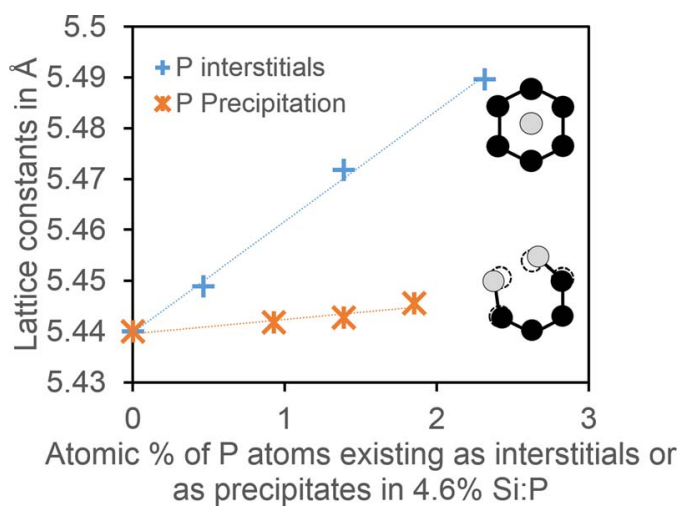

Figure 10. Variation in the relaxed lattice constants for $4.6 \%$ Si:P layer with different concentrations of $\mathrm{P}$ interstitials or $\mathrm{P}$ precipitates. It is seen that with increasing concentration of $\mathrm{P}$ atoms entering the interstitial sites or forming a precipitate configuration leads to a reduction in the tensile strain. Schematic interstitial and precipitate configurations are provided beside the respective markers. In this schematic, black circle represents $\mathrm{Si}$ and gray circle represents P. Dotted circle represents a nominal lattice site from which $\mathrm{P}$ atom is displaced in the precipitate configuration. These configurations are modeled based on References 30 and 31. 
strain in the Si:P epitaxial layer. It is also seen that for the interstitial concentration fractions as high as $30 \%$ and $50 \%$ of the total concentration, the relaxed lattice constants increase more than the reference Si lattice constant $(5.47 \AA$ ) obtained from DFT. This indicates that the layers possessing such high amounts of interstitial $\mathrm{P}$ are in compressive strain instead of tensile strain. Therefore, interstitial formation can indeed cause significant strain compensation effects in Si:P layer.

Similar to the interstitials, the formation of $\mathrm{P}$ precipitates can also lead to inactive $\mathrm{P}$ atoms and a small reduction in the tensile strain. In the case of $\mathrm{P}$ precipitates, the $\mathrm{P}$ atoms occupy first nearest neighbor sites to each other, but are not four-fold coordinated owing to the coulombic repulsion from lone electrons in $\mathrm{P}$ atoms. Such nearest neighbor donor deactivating complexes are already reported in literature. ${ }^{30}$ The lattice constants in the presence of donor deactivating complexes are extracted using the same approach as before: a fraction of the $\mathrm{P}$ atoms is assumed to be randomly located at substitutional sites, while the remaining one is supposed to be present in a precipitate configuration (Fig. 10). It is clearly seen that the lattice constants increase with the fraction of $\mathrm{P}$ atoms present in the precipitate configuration, which indicates strain compensation in the presence of the precipitates. Therefore, the formation of $\mathrm{P}$ interstitials, as well as $\mathrm{P}$ precipitates, or their combination could lead to strain compensation effects in the Si:P layers.

The reason for the interstitials or precipitates leading to strain compensation is explained in the following: When an atom with a reduced covalent radius such as $\mathrm{P}$ is present at a substitutional site, it creates tensile strain. However, when the same atom is in an interstitial site, it creates a compressive strain which tends to compensate for the tensile strain. When $\mathrm{P}$ is 4 fold coordinated to other $\mathrm{Si}$ atoms, the $\mathrm{P}$ atom pulls its Si neighbors toward itself. This results in the creation of tensile strain. On the other hand, when $\mathrm{P}$ atoms are present as precipitates, two or more $\mathrm{P}$ atoms are located as $1 \mathrm{nn}$, and there is a coulombic repulsion which forces the $\mathrm{P}$ atoms to stay away from each other. The atoms that are bonded to $\mathrm{P}$ are not pulled toward the latter but are pushed away. Hence, the precipitate configuration creates a local compressive strain. If the precipitates are randomly distributed throughout the Si:P layer, then their local compressive strains add up, leading to an overall strain compensation effect. The DFT results on precipitate formation also concurs with the experimental observation reported by Ye et al. ${ }^{9}$ Interestingly, whenever the precipitates are formed, the degree of strain compensation appears to be relatively lower than for the formation of interstitials. For e.g., when $30 \%$ of the total $\mathrm{P}$ atoms are assumed to be present at interstitial sites, the $\mathrm{Si}: \mathrm{P}$ unit cell starts to exhibit compressive strain whereas if they are assumed to be present as precipitates, they are in a state of tensile strain (albeit, the strain being lower than the precipitate free scenario). This is due to the fact that the interstitial needs to be additionally accommodated within a limited volume of the unit cell, which compresses the atoms in the vicinity of the interstitials, thereby creating a compressive strain field. Hence, the strain compensation effect is much higher for interstitials. On the other hand, the precipitate configuration involves $\mathrm{P}$ atoms that are present as $1 \mathrm{nn}$ at locally relaxed lattice site positions. In this case, only the coulombic repulsion distorts the local bonds. Hence, the local compressive strain from the coulombic repulsion is of a lower magnitude than the one from a pure interstitial $\mathrm{P}$ atom.

The proposal of interstitial/precipitate formation after annealing can be verified using RBS channeling measurements. The interstitials are completely off the lattice site while the precipitates occupy displaced positions from the lattice site and protrude into the interstitial positions. If the epi layer is defect free, then most of the channeling ions pass through the epi layer in the channeling orientation. On the contrary, if the lattice has any atoms at the interstitial sites, then the channeled ions will be backscattered. By comparing the minimum yields between the as-grown and annealed layer, the fraction of the atoms displaced to interstitial sites can be qualitatively inferred. By measuring the energy of the backscattered ion in the channeling condition, the atom that is located in the interstitial site can be identified. However, it may be difficult to identify whether the backscattering yield is owing to the presence of interstitial $\mathrm{P}$ atoms or $\mathrm{P}$ precipitates,

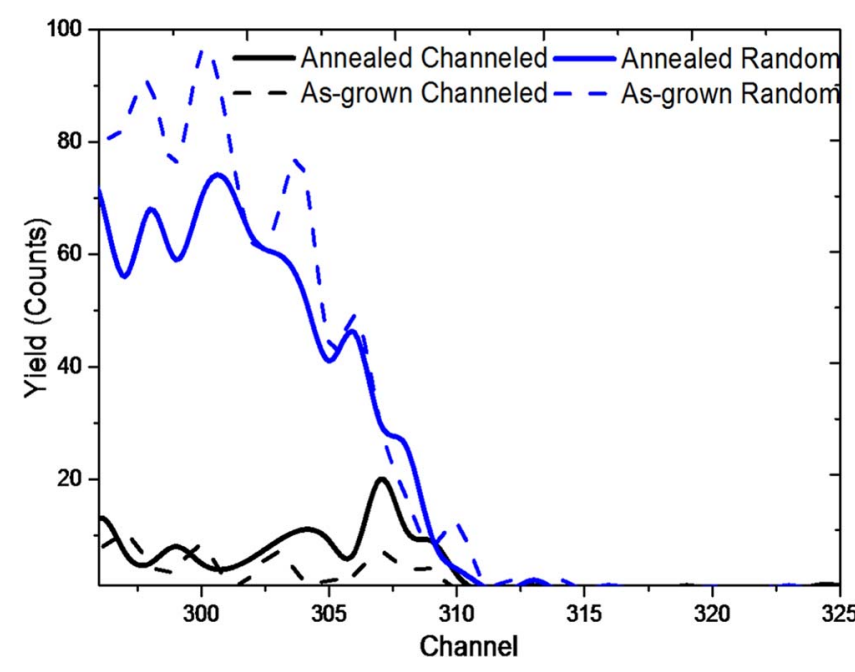

Figure 11. Rutherford backscattering spectra of the as grown and annealed Si:P layer with $4.6 \% \mathrm{P}$ in random and channeling directions. For the Si:P layers, the channeling yield in the range of 296-310 corresponds to the signal from the epi layer corresponding to P. The minimum yield, measured as the ratio of integrated counts between the corresponding channeling and random orientation, of the as grown layer is $7.9 \%$. It rises to almost $17.6 \%$ for the annealed layer, indicating the existence of $\mathrm{P}$ interstitials/precipitates after annealing.

as both of them can give rise to back scattering. The RBS channeling results for the as grown and annealed Si:P layer with 4.6\% $\mathrm{P}$ doping are shown in Fig. 11. The minimum yield for the as-grown film is measured to be $7.9 \%$, while it rises to $17.6 \%$ after laser annealing, which is almost a factor of 2 higher than the as-grown films. This qualitatively confirms a substantial increase in the $\mathrm{P}$-interstitial and/or precipitate concentration after LA.

Therefore, the strain loss after the post-epi treatments as described by Ye et al., ${ }^{9}$ and the current work can be attributed to $\mathrm{P}$ precipitation and/or the loss of $\mathrm{P}$ atoms from lattice to the interstitial sites and not necessarily to the dispersal of $\mathrm{P}_{4} \mathrm{~V}$ complexes. Having understood the evolution of strain in Si:P films, we will now understand how the formation of $\mathrm{P}_{4} \mathrm{~V}$ complexes explains the observed carrier saturation in Si:P films.

Electrical properties explained by $P-V$ complexes.-When $\mathrm{P}$ atoms are 4 fold coordinated (i.e. active), they act as active dopants. On the other hand, $\mathrm{P}$ atoms in the $\mathrm{P}-\mathrm{V}$ complexes are just 3 fold coordinated to $\mathrm{Si}$. The fourth valence electron is bonded to a vacancy. The $\mathrm{P}$ bonded to the vacancy is thus no longer a dopant but an $\mathrm{E}$ center. ${ }^{32,33}$ The formation of such an E center acting as an acceptor level is already known. ${ }^{34}$ Therefore, the formation of $E$ centers can lead to carrier trapping. The electronic picture of the P-V complexes can be provided by Bader population analysis technique. ${ }^{17}$

The Bader population analysis on the $4.6 \%$ Si:P system with $\mathrm{P}$ atoms bonded to vacancies as well as on the active ones (4 fold coordination) reveals that, in absence of a vacancy, the integrated charge on a 4 fold coordinated $\mathrm{P}$ is close to $8.3|\mathrm{e}|$, while the one on the $\mathrm{P}$ bonded to a vacancy is $7.9|\mathrm{e}|$. This difference in electronic population indicates that $\mathrm{P}$ atoms bonded to the vacancies have a lower electronic density surrounding them than what is available in the active four fold coordinated $\mathrm{P}$ atom. This suggests that $\mathrm{P}$ atoms bonded to the P-V complexes are inactive.

The difference in Bader charges between the active $\mathrm{P}$ and the one bonded to the vacancy can be explained by the nature of the $\mathrm{sp}^{3}$ hybridization between the orbitals taking place in $\mathrm{Si}$, where the electrons in the $2 \mathrm{~s}$ orbital are promoted to the $2 \mathrm{p}$ level on the same atomic site to form an $\mathrm{sp}^{3}$ hybridized state with 4 electrons. In this hybridized state, one electron occupies each of the available energy levels to offer a total of 4 unpaired electrons. Following the octet rule, there is a room to accommodate an additional electron on each 


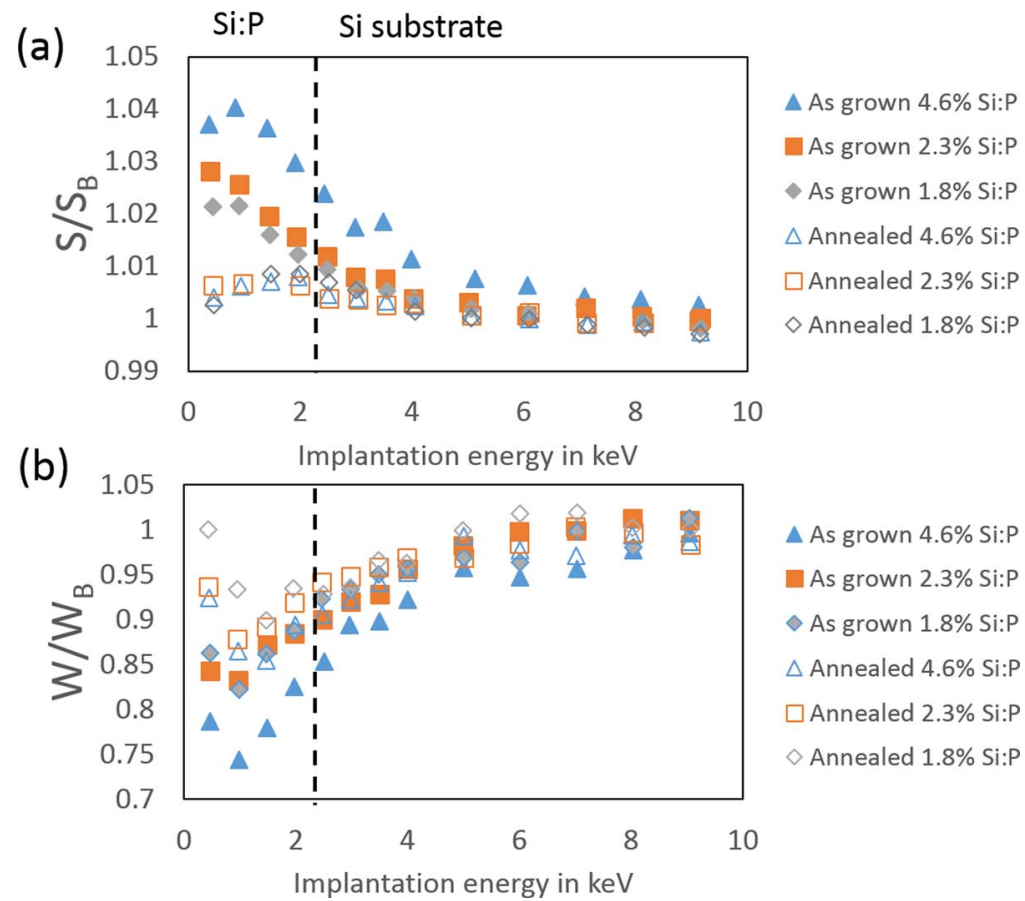

Figure 12. $\mathrm{S}$ and $\mathrm{W}$ parameters measured in $\mathrm{Si}: \mathrm{P}$ epi layers, normalized to that of bulk $\mathrm{Si}$, plotted as a function of implantation energy for the as grown and annealed Si:P layers with three different $P$ concentrations. a) Increasing $S$ parameter with increasing $\mathrm{P}$ concentration reflects an increasing vacancy concentration/size. b) The $\mathrm{W}$ parameters are complementary to $\mathrm{S}$ parameters and the low value of the normalized $\mathrm{W}$ parameters indicates the presence of vacancy defects in the epi layer. On the other hand, the $\mathrm{S}(\mathrm{W})$ parameters reduce (increase) on annealing, indicating vacancy reduction in the post-epi annealed layers.

of the levels. In this way, a $\mathrm{Si}$ binds with four other $\mathrm{Si}$ atoms to form a tetrahedral configuration. When $\mathrm{P}$ is an active dopant, it also undergoes a similar $\mathrm{sp}^{3}$ hybridization with $\mathrm{Si}$. In this case, the $\mathrm{s}$ orbital of $\mathrm{P}$ owns 2 electrons, while the $\mathrm{p}$ orbital owns 3 electrons. The $\mathrm{sp}^{3}$ hybridization of $\mathrm{P}$ involves a total of 5 electrons, of which only 4 bond to other $\mathrm{Si}$ atoms. Hence, the fifth electron needs to be promoted to the conduction level. When a $\mathrm{P}$ atom bonds to 4 other $\mathrm{Si}$ atoms in a tetrahedral way, the extra electron in $\mathrm{P}$ becomes a charge carrier and gives rise to the conduction properties. In the dopant state, the total number of electrons on the active $\mathrm{P}$ is 9 ( 4 electrons from $\mathrm{P}, 4$ shared electrons from $\mathrm{Si}$ and 1 electron promoted to the conduction level in $\mathrm{P})$. The calculated Bader charge of $8.3|\mathrm{e}|$ qualitatively agrees with the charges localized around $\mathrm{P}$.

When $\mathrm{P}$ is bonded to a vacancy, it is 3 -fold coordinated and hence only three of its $\mathrm{sp}^{3}$ hybridized orbitals are filled by $\mathrm{Si}$. As a result, there is room in the fourth level to accomodate the extra electron, which consequently is no longer promoted to the conduction level. Thus, the total number of electrons in the $\mathrm{P}$ domain is expected to be close to 8 (5 electrons from $\mathrm{P}$ and 3 electrons from $\mathrm{Si}$ ), and this is in good qualitative agreement with the calculated Bader charge of 7.9|e| obtained for inactive $P$.

Thus, the formation of $\mathrm{P}_{4} \mathrm{~V}$ complexes leads to the deactivated dopants and doesn't contribute to conductivity in the as grown films. Thanks to their negative enthalpy they are spontaneous at high $\mathrm{P}$ concentrations $\left(\mathrm{P}>1 \mathrm{E} 20 \mathrm{at} / \mathrm{cm}^{3}\right)$. Hence, more $\mathrm{P}$ atoms form these complexes as the total $\mathrm{P}$ concentration increases. It is obvious that this leads to a saturation in the active carrier concentration. Hence, these complexes limit the active carriers available for conduction. Additionally, these complexes can also act as scattering centers, thereby contributing to mobility losses. A combination of carrier saturation and continuous decrease in the hall mobilities eventually leads to the increase in resistivity at high $\mathrm{P}$ concentrations.

On the other hand, as will be discussed in the next section, annealing primarily leads to vacancy reduction thereby activating a fraction of $\mathrm{P}$ atoms bonded to these complexes. As a result, the carrier concentration increases and the resistivity also reduces.

\section{Experimental Verification of $\mathrm{P}_{\mathbf{4}} \mathrm{V}$ Complexes Using PAS}

Although first principle simulations predict the existence of $\mathrm{P}_{4} \mathrm{~V}$ complexes, it is also essential to validate their physical presence in
Si:P films. Positron annihilation spectroscopy is used to verify the existence of these complexes. In our studies, we have used Doppler broadening spectroscopy (DOBS) to study the Si:P layers.

Verification of the P-V complexes.-Figures $12 \mathrm{a}$ and $12 \mathrm{~b}$ show the extracted $\mathrm{S}$ and $\mathrm{W}$ parameters of the as grown (filled symbols) and annealed Si:P layers (open symbols) as a function of $\mathrm{e}^{+}$-implantation energy. Currently, as the 'standard' S and W parameters are not available for completely vacancy free Si:P films, the extracted S and W parameters are normalized with respect to a defect free Si reference.

First, the as-grown layers are discussed. For an implantation energy $<2.1 \mathrm{keV}$, the positron primarily interacts with the epi layer and beyond $2.1 \mathrm{keV}$, the positron interacts with the bulk. For the as grown layers, a characteristic peak (dip) is seen in the $\mathrm{S}(\mathrm{W})$ parameter, at approximately $1 \mathrm{keV}$, which corresponds to saturation positron trapping in the epi layer. This points to the fact that the positrons implanted with the said energy has been trapped and annihilated in the main type of open volume defects present within the Si:P layer. E.g. these main open volume defects may exist as $\mathrm{P}_{4} \mathrm{~V}$ complexes. The increase in $\mathrm{S}$ parameter with a growing $\mathrm{P}$ concentration illustrates that the size/concentration of the vacancy complexes present in these films also increases.

The extracted $\mathrm{S}$ and $\mathrm{W}$ parameters provide better insights into the nature of positron annihilation states, whenever they are plotted as a function of each other in an S-W plane. ${ }^{35}$ Figure 13 shows the W(S) plot for the studied samples. The evolution in normalized $\mathrm{W}$ and $\mathrm{S}$ points is indicated using the black curve (starting from 1). The arrows in the black curve represent the direction of increasing $\mathrm{e}^{+}$implantation energy. It shows that the $\mathrm{S}$ parameter increases and reaches a maximum as indicated by the dotted circle, and then begins to further decrease. On the other hand, the $\mathrm{W}$ parameter exhibits a complementary trend to the behavior of the $\mathrm{S}$ parameter. The maximum $\mathrm{S}$ value in this plot corresponds to the saturation trapping in the epi layer and its decrease arises from the interaction of the positrons with the substrate. The data points of the as-grown samples fall all on the same line. As we reported elsewhere, ${ }^{27}$ using a high resolution CDOBS measurement technique enabled us to identify the chemical surroundings of the vacancies as well. It was deduced that vacancies were decorated with $\mathrm{P}$ atoms similar to $\mathrm{P}_{4} \mathrm{~V}$ complexes, which were predicted in the Influence of vacancy on $\mathrm{P}$ arrangement section of this paper. However, due to 


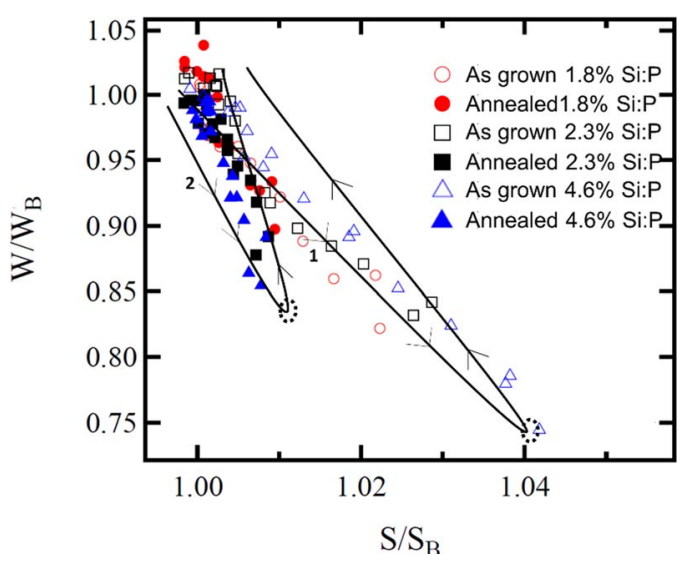

Figure 13. W(S)-plot for Si:P layers with different $\mathrm{P}$ concentrations. The arrows represent the direction of increasing positron implantation energy starting with (1) for the as-grown layers and (2) for the annealed layers. The two circles indicate the maximum $\mathrm{S}$ parameter obtained for the as-grown and annealed layers.

the ambiguity of positrons behavior in $\mathrm{P}$ decorated divacancies, the existence of divacancies was also not ruled out.

The remaining question that needs to be addressed is whether these complexes dissolve upon annealing and contribute to the increase in the carrier concentration. To investigate this scenario, PAS measurements were performed on the annealed layers using the same experimental conditions as before, as shown in Figs. 12 and 13.

In Fig. 12, the $S(W)$ parameters of the annealed layers are relatively lower (higher) than the corresponding values in the as-grown layers. This indicates that the amount of open volume defects decreases upon annealing. Additionally, by plotting the normalized S and W parameters in the S-W plane, (closed symbols in Fig. 13) one observes that the slope of the line formed by the $\mathrm{S}-\mathrm{W}$ points of the annealed layers is different from that of the as-grown films. This suggests that the dominating positron annihilation state within the annealed Si:P layer is also different from the as-grown films. For the annealed layers, the annihilation state within the Si:P layer appears to be the same for all the samples. This state is farther away from the as-grown films and confirms that the annealed samples do not contain significant amounts of positron traps, i.e. vacancies.

Thus, PAS characterization confirms the existence of $\mathrm{P}_{4} \mathrm{~V}$ complexes in the as-grown $\mathrm{Si}: \mathrm{P}$ films and the reduction of these complexes upon annealing. Hence, the saturation in active carrier concentration in the as grown films is due to the manifestation of these complexes and they reduce on annealing, explaining the increase in active carrier concentration.

\section{Conclusions}

In this work, we investigated the microstructural origin of strain and conductivity in heavily $\mathrm{P}$ doped Si:P epitaxial layers, targeted for S/D stressor applications in n-FinFETs. Although the Si:P epitaxial layers are touted to provide excellent conductivity as well as tensile strain, the as grown layers compromise on conductivity and active carrier concentration albeit providing strain. Upon annealing, the conductivity and the active dopant concentration increase concurrent with a slight strain reduction. We studied whether the formation of local $\mathrm{Si}_{3} \mathrm{P}_{4}$ complexes (or $\mathrm{P}_{4} \mathrm{~V}$ ) complexes can explain the observed evolution in strain and electrical properties. A combination of DFT and physical characterization techniques were used to address this issue.

Using DFT, it is found that $\mathrm{P}-\mathrm{V}$ complexes in $\mathrm{P}_{4} \mathrm{~V}$ or $\mathrm{P}_{6} \mathrm{~V}_{2}$ configurations are thermodynamically favorable (i.e., possess negative formation enthalpies). The existence of $\mathrm{P}_{4} \mathrm{~V}$ is also confirmed using PAS studies. Therefore, local complexes do form in Si:P epitaxial layers. However, these complexes are not exclusively responsible for the development of tensile strain in the as-grown films. Indeed, DFT results indicated that the as-grown Si:P films with and without local complexes possessed comparable lattice constants. The strain developed in Si:P films is solely attributed to differences in covalent radii between $\mathrm{P}$ and $\mathrm{Si}$. Whereas the slight reduction in tensile strain after annealing is attributed to the formation of $\mathrm{P}$ interstitials or precipitates. The formation of interstitials or precipitates is also confirmed by an increased minimum yield of annealed Si:P layers, measured using RBS ion channeling.

Pertaining to the evolution of electrical properties, the saturation in active carrier concentration in the as-grown $\mathrm{Si}: \mathrm{P}$ layers is attributed to the formation of $\mathrm{P}_{4} \mathrm{~V}$ complexes. Beyond a $2.3 \% \mathrm{P}$ concentration, the added $\mathrm{P}$ atom goes to form $\mathrm{P}_{4} \mathrm{~V}$ complexes due to the negative thermodynamic enthalpy of the complexes. These complexes can also act as scattering centers leading to mobility losses. The carrier saturation together with continuous loss in mobility lead to an increase in resistivity in the as-grown $\mathrm{Si}: \mathrm{P}$ epitaxial layers. Upon annealing, the $\mathrm{P}-\mathrm{V}$ complexes are dissolved leading to an increase in the active carrier concentration. The dissolution of $\mathrm{P}-\mathrm{V}$ complexes is also confirmed using PAS studies. Thus, the formation of $\mathrm{P}_{4} \mathrm{~V}$ complexes very well explains the observed evolution in electrical properties but not the evolution in tensile strain.

\section{Acknowledgments}

We would also like to extend our thanks to Bruker for their support on XRD and RSM measurements, to our pilot line, the logic program of imec, and to all core partners. Yosuke Shimura thank FWO for granting him a Pegasus Marie Curie post-doctoral fellowship.

\section{ORCID}

Sathish kumar Dhayalan (10 https://orcid.org/0000-0003-1607-3370 Roger Loo (D) https://orcid.org/0000-0003-3513-6058

\section{References}

1. C. Merckling, S. Jiang, Z. Liu, N. Waldron, G. Boccardi, R. Rooyackers, Z. Wang, B. Tian, M. Pantouvaki, N. Collaert, J. Van Campenhout, M. Heyns, D. Van Thourhout, W. Vandervorst, and A. Thean, ECS Trans., 66(4), 107 (2015).

2. A. Vandooren, D. Leonelli, R. Rooyackers, A. Hikavyy, K. Devriendt, M. Demand, R. Loo, G. Groeseneken, and C. Huyghebaert, Solid. State. Electron., 83, 50 (2013).

3. K.-M. Tan, T.-Y. Liow, R. T. P. Lee, K. M. Hoe, C.-H. Tung, N. Balasubramanian, G. S. Samudra, and Y.-C. Yeo, IEEE Electron Device Lett., 28, 905 (2007).

4. T.-Y. Liow, K.-M. Tan, D. Weeks, R. Lee, M. Zhu, K.-M. Hoe, C.-H. Tung, M. Bauer, J. Spear, S. G. Thomas, G. S. Samudra, N. Balasubramanian, and Y.-C. Yeo, IEEE Trans. Electron Devices, 55, 2475 (2008).

5. N. Loubet, T. Adam, M. Raymond, Q. Liu, K. Cheng, R. Sreenivasan, A. Reznicek, P. Khare, W. Kleemeier, V. Paruchuri, B. Doris, and R. Sampson, Thin Solid Films, 520, 3149 (2012).

6. E. Rosseel, H. B. Profijt, A. Y. Hikavyy, J. Tolle, S. Kubicek, G. Mannaert, C. L'abbe, K. Wostyn, N. Horiguchi, T. Clarysse, B. Parmentier, S. Dhayalan, H. Bender, J. W. Maes, S. Mehta, and R. Loo, ECS Trans., 64(6), 977 (2014).

7. C.-N. Ni, X. Li, S. Sharma, K. V. Rao, M. Jin, C. Lazik, V. Banthia, B. Colombeau, N. Variam, A. Mayur, H. Chung, R. Hung, and A. Brand, IEEE Symp. VLSI Technol. pp. T118 (2015)

8. K. D. Weeks, S. G. Thomas, P. Dholabhai, and J. Adams, Thin Solid Films, 520, 3158 (2012).

9. Z. Ye, S. Chopra, R. Lapena, Y. Kim, and S. Kuppurao, ECS Trans., 50(9), 1007 (2013).

10. M. Bauer and S. Thomas, ECS Trans., 33(6), 629 (2010).

11. J. M. Hartmann, V. Benevent, J. P. Barnes, M. Veillerot, and C. Deguet, Semicond. Sci. Technol., 28, 25017 (2013).

12. X. Li, A. Dube, Z. Ye, S. Sharma, Y. Kim, and S. Chu, ECS Trans., 64(6), 959 (2014).

13. RADS software, http://www.jvsemi.com/products/compound/rads-software

14. P. Giannozzi, S. Baroni, N. Bonini, M. Calandra, R. Car, C. Cavazzoni, D. Ceresoli, G. L. Chiarotti, M. Cococcioni, I. Dabo, A. Dal Corso, S. de Gironcoli, S. Fabris, G. Fratesi, R. Gebauer, U. Gerstmann, C. Gougoussis, A. Kokalj, M. Lazzeri, L. Martin-Samos, N. Marzari, F. Mauri, R. Mazzarello, S. Paolini, A. Pasquarello, L. Paulatto, C. Sbraccia, S. Scandolo, G. Sclauzero, A. P. Seitsonen, A. Smogunov, P. Umari, and R. M. Wentzcovitch, J. Phys. Condens. Matter, 21, 395502 (2009).

15. J. Perdew, K. Burke, and M. Ernzerhof, Phys. Rev. Lett., 77, 3865 (1996).

16. R. F. W. Bader, Chem. Rev., 91, 893 (1991).

17. R. F. W. Bader, P. J. MacDougall, and C. D. H. Lau, J. Am. Chem. Soc., 106, 1594 (1984).

18. J. Kujala, Point Defects in Nanocrystals and Semiconductors Studied with Positron Annihilation Spectroscopy, Aalto University, 2016. 
19. S.-L. Sihto, J. Slotte, J. Lento, K. Saarinen, E. Monakhov, A. Kuznetsov, and B. Svensson, Phys. Rev. B, 68, 1 (2003).

20. S. Kilpeläinen, K. Kuitunen, F. Tuomisto, J. Slotte, E. Bruno, S. Mirabella, and F. Priolo, Semicond. Sci. Technol., 24, 15005 (2008).

21. P. Hautojärvi, C. Corbel, and K. Saarinen, Identification of Defects in Semiconductors, Vol. 51A, P. 209. (Academic Press, San Diego, 1988).

22. M. V. Fischetti, Phys. Rev. B, 44, 5527 (1991).

23. M. Huang, Y. P. Feng, A. T. L. Lim, and J. C. Zheng, Phys. Rev. B, 69, 054112 (2004),

24. H. Rücker, M. Methfessel, B. Dietrich, K. Pressel, and H. Osten, Phys. Rev. B, 53 1302 (1996)

25. M. G. Ganchenkova, V. a. Borodin, and R. M. Nieminen, Nucl. Instruments Methods Phys. Res. Sect. B Beam Interact. with Mater. Atoms, 228, 218 (2005).

26. R. Chen, B. Trzynadlowski, and S. T. Dunham, J. Appl. Phys., 115, 54906 (2014)

27. S. K. Dhayalan, J. Kujala, J. Slotte, G. Pourtois, E. Simoen, E. Rosseel, A. Hikavyy, Y. Shimura, S. Jacovo, A. Stesmans, R. Loo, and W. Vandervorst, Appl. Phys. Lett., 108, 82106 (2016).
28. While PBE is used in the present work, usually LDA is more suitable for better description of bond lengths. However, LDA has its own drawbacks when it comes to description of the electronic structure, which is of prime importance for Si:P films. Hence, PBE is used in the present work.

29. G. Masetti, M. Severi, and S. Solmi, IEEE Trans. Electron Devices, 30, 764 (1983).

30. Y.-S. Kim, E.-C. Lee, and K. J. Chang, Phys. Rev. Lett., 91, 125503 (2003).

31. X-Y Liu, W. Windl, K. M. Beardmore, and M. P. Masquelier, Appl. Phys. Lett., 82 , 1839 (2003).

32. G. D. Watkins and J. W. Corbett, Phys. Rev., 134, A1359 (1964).

33. A. N. Larsen, A. Mesli, K. Bonde Nielsen, H. K. Nielsen, L. Dobaczewski, J. Adey, R. Jones, D. W. Palmer, P. R. Briddon, and S. Öberg, Phys. Rev. Lett., 97, 106402 (2006).

34. A. N. Larsen and A. Mesli, Phys. B Condens. Matter, 401-402, 85 (2007).

35. Usually the abscissa is the normalized $\mathrm{S}$ parameter and the ordinate is normalized $\mathrm{W}$ parameter 